\title{
Longevity-associated NADH dehydrogenase subunit-2 237 Leu/Met polymorphism influences the effects of alcohol consumption on serum uric acid levels in nonobese Japanese men
}

\author{
Akatsuki Kokaze $\cdot$ Mamoru Ishikawa • \\ Naomi Matsunaga $\cdot$ Masao Yoshida . \\ Masao Satoh $\cdot$ Koji Teruya $\cdot$ Rie Honmyo • \\ Misako Yorimitsu · Yumi Masuda · Yoshiko Uchida · \\ Yutaka Takashima \\ Received: 31 March 2006/ Accepted: 15 May 2006/Published online: 8 August 2006 \\ (C) The Japan Society of Human Genetics and Springer-Verlag 2006
}

\begin{abstract}
NADH dehydrogenase subunit-2 237 leucine/methionine (ND2-237 Leu/Met) polymorphism is reportedly associated with longevity in the Japanese population. The ND2-237Met genotype may confer resistance to cardiovascular and cerebrovascular atherogenic diseases. Hyperuricemia is one of the risk factors for cardiovascular disease. To investigate whether ND2-237 Leu/Met polymorphism is associated with serum uric acid (SUA) levels, we conducted a cross-sectional study in 321 healthy Japanese male subjects. In nonobese (body mass index, BMI $<25$ ) male subjects, interaction between ND2-237 Leu/Met genotypes and drinking frequency on SUA levels was observed $(P=0.031)$. The SUA levels were significantly higher in daily drinkers with ND2-237Leu than in non-daily drinkers with ND2-237Leu $(P=0.018)$. In
\end{abstract}

A. Kokaze $(\bowtie) \cdot$ M. Ishikawa $\cdot$ N. Matsunaga

M. Yoshida $\cdot$ R. Honmyo $\cdot$ M. Yorimitsu $\cdot$ Y. Masuda $\cdot$

Y. Uchida $\cdot$ Y. Takashima

Department of Public Health, Kyorin University School

of Medicine, 6-20-2 Shinkawa, Mitaka-shi,

Tokyo 181-8611, Japan

e-mail: dawn@kyorin-u.ac.jp

M. Ishikawa

Mito Red Cross Hospital, 3-12-48 Sannomaru,

Mito-shi, Ibaraki 310-0011, Japan

M. Satoh

Department of Allergy and Immunology,

Saitama Medical School, 38 Morohongo, Moroyama,

Iruma-gun, Saitama 350-0495, Japan

K. Teruya

Department of Public Health, Kyorin University School

of Health Sciences, 476 Miyashita-machi,

Hachioji-shi, Tokyo 192-8508, Japan nonobese men, after adjustment for covariates, daily drinkers with ND2-237Leu had a significantly higher odds ratio (OR) for hyperuricemia $(\mathrm{SUA} \geq 6.5 \mathrm{mg} / \mathrm{dl}$ : vs. daily drinkers with ND2-237Met, OR=3.26, 95\% confidence interval (CI) 1.14-9.29; vs. non-daily drinkers with ND2-237Leu, OR=3.22, 95\% CI 1.397.45; SUA $\geq 7.0 \mathrm{mg} / \mathrm{dl}$ : vs. non-daily drinkers with ND2237Met, OR=3.53, 95\% CI 1.00-12.4). However, in obese $(\mathrm{BMI} \geq 25)$ men, no significant interaction between ND2-237 Leu/Met polymorphism and habitual drinking on SUA levels or on the risk for hyperuricemia was observed. These results suggest that ND2-237 Leu/Met polymorphism modulates the effects of daily alcohol consumption on SUA levels in nonobese Japanese men.

Keywords Uric acid · Hyperuricemia · Longevity · NADH dehydrogenase · Polymorphism · Daily alcohol drinking $\cdot$ Gene-environmental interaction

\section{Introduction}

Mitochondrial DNA cytosine/adenine (Mt5178 C/A) polymorphism, which also known as NADH dehydrogenase subunit-2 237 leucine/methionine (ND2-237 Leu/Met) polymorphism, is reportedly associated with longevity in the Japanese population (Tanaka et al. 1998). The frequency of the ND2-237 Met (Mt5178A) genotype is significantly higher in Japanese centenarians than in the general population (Tanaka et al. 1998) and it is reported that Japanese individuals with ND2-237Leu (Mt5178C) are more susceptible to cardiovascular (Mukae et al. 2003; Takagi et al. 2004) or cerebrovascular atherosclerotic diseases (Ohkubo et al. 
2002) compared to those with ND2-237Met. The antiatherogenic effects of the ND2-237Met genotype may facilitate longevity in individuals with ND2-237Met when compared to those with ND2-237Leu.

Hyperuricemia, the prevalence of which is higher in men than in women (Wortmann 2002), is a reported risk factor for both gout and cardiovascular disease (Alderman and Aiyer 2004; Johnson et al. 2003; Tomita et al. 2000). Several epidemiological studies have reported that alcohol intake is a risk factor for hyperuricemia and gout (Campion et al. 1987; Lin et al. 2000; Loenen et al. 1990; Kono et al. 1994; Nakanishi et al. 1999; Sugie et al. 2005). Moreover, genetic epidemiological research has shown that alcohol dehydrogenase 2 (ADH2) genotype (Hashimoto et al. 2002) or endothelial constitutive nitric oxide synthase (ecNOS) genotype (Nishio et al. 2005) influences the effects of alcohol consumption on serum uric acid (SUA) levels in the Japanese male population. We previously reported the interaction between ND2-237 Leu/Met polymorphism and daily alcohol intake on blood pressure (Kokaze et al. 2004), serum triglyceride (TG) levels (Kokaze et al. 2003), and fasting plasma glucose (FPG) levels and response to 75 -g oral glucose tolerance tests (75-g-OGTT) (Kokaze et al. 2005) in healthy Japanese men. To our knowledge, there have been no reports regarding the association between longevityassociated ND2-237 Leu/Met polymorphism and SUA levels, or the effect of ND2-237 Leu/Met polymorphism and drinking frequency on SUA levels. With regard to personalized prevention of hyperuricemia using genetic information, it is medically useful to elucidate these relationships.

The objective of this paper was to investigate the relationship between ND2-237 Leu/Met and SUA levels, and the interaction between ND2-237 Leu/Met polymorphism and daily alcohol intake on SUA levels in healthy Japanese male subjects.

\section{Materials and methods}

\section{Subjects}

Participants were recruited from among individuals visiting the Mito Red Cross Hospital, Japan, for regular medical check-ups between August 1999 and August 2000. This study was conducted in accordance with the Declaration of Helsinki and was approved by the Ethics Committee of the Kyorin University School of Medicine, Japan. Written informed consent was obtained from 602 volunteers before participation. Among these, 327 men not taking any medication for hyperuricemia, hypertension, hyperlipidemia, or diabetes were enrolled in this study. Six individuals with unclear drinking frequency were excluded. Therefore, the subjects comprised 321 Japanese men (age $53.0 \pm 7.7$ years; mean $\pm \mathrm{SD}$ ).

Clinical characteristics of subjects

Determination of blood chemical [SUA levels, serum total cholesterol levels, serum high-density lipoprotein (HDL) cholesterol levels, serum TG levels, serum gamma-glutamyltranspeptidase $(\gamma$-GTP) levels, and serum creatinine levels] and physical [weight, height, systolic blood pressure (SBP), and diastolic blood pressure (DBP)] data was conducted as described previously (Kokaze et al. 2001, 2004). Briefly, venous blood was drawn after a minimum fasting period of $12 \mathrm{~h}$. The body mass index (BMI) was defined as the ratio of subject weight $(\mathrm{kg})$ to the square of subject height $(\mathrm{m})$. A survey of drinking and smoking habits was performed by means of a questionnaire. Habitual drinking was classified based on drinking frequency (daily drinkers, occasional drinkers, including those who drink several times per week; and non- or ex-drinkers, which include those who drink a few times per month). Habitual smoking was classified into non-smokers (never smoke or former smokers) and current smokers, who consume one or more cigarettes per day. Hyperuricemia was defined as SUA $\geq 6.5 \mathrm{mg} / \mathrm{dl}$ or SUA $\geq 7.0 \mathrm{mg} / \mathrm{dl}$, since both diagnostic levels are widely applied (Alderman and Aiyer 2004; Japanese Society of Gout and Nucleic Acid metabolism 2002; Johnson et al. 2003; Tomita et al. 2000).

\section{Genotyping}

Genotyping methods were as described previously (Kokaze et al. 2001). Briefly, DNA was extracted from white blood cells. Polymerase chain reaction (PCR) was performed with $50 \mathrm{ng}$ of genomic DNA in a $50-\mu \mathrm{l}$ buffer containing $1.5 \mathrm{mM} \mathrm{MgCl} 2,1.25 \mathrm{mM}$ dNTPs, each primer at $1 \mu \mathrm{M}$ and $0.5 \mathrm{U}$ of Amplitaq DNA polymerase (GeneAmp, Perkin Elmer, USA). After initial denaturation at $94^{\circ} \mathrm{C}$ for $5 \mathrm{~min}$, PCR cycling (denaturation at $94^{\circ} \mathrm{C}$ for $30 \mathrm{~s}$, annealing at $60^{\circ} \mathrm{C}$ for $60 \mathrm{~s}$, and polymerase extension at $72^{\circ} \mathrm{C}$ for $90 \mathrm{~s}$ ) was repeated for 40 cycles, followed by a final extension at $72^{\circ} \mathrm{C}$ for $10 \mathrm{~min}$. The primers used were $5^{\prime}$-CTTAGCATACTCCTCAATTACCC-3' and 5'-CTGAATTCTTCGATAATGGCCCA-3'. PCR products were digested with the restriction enzyme AluI. The absence of an AluI site was designated ND2-237Met (Mt5178A), and the presence of this restriction site was designated ND2-237Leu (Mt5178C). 
Statistical analyses

For all analyses, the subjects were divided into two groups based on BMI: "BMI $<25$ (nonobese)" $(n=241)$ and "BMI $\geq 25$ (obese)" $(n=80)$. The cut-off point $(\mathrm{BMI}=25)$ was determined based on reports regarding the classification of obesity for the Japanese population (Matsuzawa et al. 2000). Statistical analyses were performed using SAS software, version 8.2 for Windows. Student's $t$ test was used to compare the mean values of clinical characteristics between the ND2-237Leu genotype and the ND2-237Met genotype. For consideration and evaluation of interactions between ND2$237 \mathrm{Leu} / \mathrm{Met}$ polymorphism and habitual drinking or habitual smoking with regard to SUA levels, we performed the analysis of covariates (ANCOVA). In ANCOVA or multiple regression analysis, ND2-237 Leu/Met genotype (ND2-237Leu=0, ND2-237Met=1), habitual drinking (non-/ex-/occasional, namely, nondaily drinkers $=0$, daily drinkers $=1$ ) and habitual smoking (non-smokers=0, current smokers $=1$ ) were numerically coded. Age, BMI, SBP, DBP, logarithmtransformed serum TG levels, logarithm-transformed serum $\gamma$-GTP levels, and serum creatinine levels were included as covariates in the models. Serum TG levels and serum $\gamma$-GTP levels were logarithm-transformed, as they were not normally distributed. Multiple logistic regression analysis was used to calculate odds ratios for hyperuricemia (SUA $\geq 6.5 \mathrm{mg} / \mathrm{dl}$ or $\mathrm{SUA} \geq 7.0 \mathrm{mg} / \mathrm{dl}$ ). Differences with $P$ values of less than 0.05 were considered to be statistically significant.

\section{Results}

Although not statistically significant ( $\chi^{2}$ test, $P=0.108$ ), the frequency of ND2-237Met was higher in $\mathrm{BMI} \geq 25$ subjects (47.5\%: 38/80) than in $\mathrm{BMI}<25$ subjects (37.3\%: 90/241) (Table 1). In nonobese subjects, serum HDL cholesterol levels were significantly higher in men with ND2-237Met than in those with ND2-237Leu $(P=0.023)$. However, no significant differences in any characteristics were observed between the ND2-237 Leu/Met genotypes in obese subjects.

In ANCOVA (Table 2), logarithm-transformed serum TG levels $(P=0.002)$, serum creatinine levels $(P<0.001)$, and the interaction between ND2-237 Leu/ Met genotype and habitual drinking $(P=0.031)$ were significantly associated with SUA levels in $\mathrm{BMI}<25$ subjects. However, in $\mathrm{BMI} \geq 25$ subjects, neither independent variables nor interactions between ND2-237 Leu/Met genotypes and lifestyle factors were found to be associated with SUA levels.
In multiple regression analysis (Table 3 ), habitual drinking (daily alcohol intake), logarithm-transformed serum TG levels, and serum creatinine levels were significantly and positively associated with SUA levels in nonobese $(\mathrm{BMI}<25)$ subjects with $\mathrm{ND} 2-237 \mathrm{Leu}$ $(P=0.002,0.004$, and $<0.001$, respectively). In nonobese ND2-237Met genotypic men, no significant associations were observed. In obese $(\mathrm{BMI} \geq 25)$ men with ND2-237Leu or in those with ND2-237Met, no significant associations were observed (data not shown).

After adjustment for age, BMI, SBP, DBP, logarithm-transformed serum TG levels, logarithm-transformed serum $\gamma$-GTP levels, serum creatinine levels, and habitual smoking, in $\mathrm{BMI}<25$ subjects, SUA levels were significantly higher in daily drinkers with ND2-237Leu than in non-daily drinkers with ND2-237Leu ( $P=0.018$ : Bonferroni's multiple comparison test) (Table 4). No statistically significant differences were observed between daily drinkers and non-daily drinkers with the ND2-237Met genotype. In $B M I \geq 25$ subjects, no significant differences were observed.

In order to further explore the relationship among the ND2-237 Leu/Met genotypes, habitual drinking, and SUA levels, multiple logistic regression analysis for hyperuricemia (SUA $\geq 6.5 \mathrm{mg} / \mathrm{dl}$ or $\mathrm{SUA} \geq 7.0 \mathrm{mg}$ / dl) was undertaken. In BMI $<25$ subjects (Table 5), daily drinkers with ND2-237Leu had a significantly higher odds ratio (OR) for $S U A \geq 6.5 \mathrm{mg} / \mathrm{dl}$ when compared to non-daily drinkers with ND2-237Met $(\mathrm{OR}=2.61,95 \%$ confidence interval (CI) 1.17-5.84, $P=0.020)$, to daily drinkers with ND2-237Met $(\mathrm{OR}=4.12,95 \%$ CI $1.65-10.28, P=0.002)$, to non-daily drinkers with ND2-237Leu (OR=3.09, 95\% CI 1.546.20, $P=0.002$ ), or to a group comprising the three other subgroups $(\mathrm{OR}=3.14,95 \%$ CI 1.72-5.73, $P<0.001)$. After adjusting for age, BMI, habitual smoking, SBP, DBP, logarithm-transformed serum TG levels, logarithm-transformed serum $\gamma$-GTP levels, and serum creatinine levels, except when compared to non-daily drinkers with ND2-237Met, the OR for SUA levels $\geq 6.5 \mathrm{mg} / \mathrm{dl}$ in daily drinkers with ND2-237Leu remained significant (vs. daily drinkers with ND2-237Met: OR=3.26, 95\% CI 1.14-9.29, $P=0.027$; vs. non-daily drinkers with ND2-237Leu: $\mathrm{OR}=3.22$, 95\% CI 1.39-7.45, $P=0.006$; vs. group comprising the three other subgroups: $\mathrm{OR}=2.90,95 \%$ CI $1.49-5.65, P=0.002$, respectively). The OR for SUA levels $\geq 7.0 \mathrm{mg} / \mathrm{dl}$ was significantly higher in daily drinkers with ND2-237Leu when compared to non-daily drinkers with ND2-237Met, non-daily drinkers with ND2-237Leu, or the group composed 
Table 1 Clinical characteristics of study subjects by ND2-237 Leu/Met genotype

\begin{tabular}{|c|c|c|c|c|c|c|}
\hline & \multicolumn{3}{|l|}{$\mathrm{BMI}<25$} & \multicolumn{3}{|l|}{$\mathrm{BMI} \geq 25$} \\
\hline & $\begin{array}{l}\text { ND2-237Leu } \\
(N=151)\end{array}$ & $\begin{array}{l}\text { ND2-237Met } \\
(N=90)\end{array}$ & $P$ value & $\begin{array}{l}\text { ND2-237Leu } \\
(N=42)\end{array}$ & $\begin{array}{l}\text { ND2-237Met } \\
(N=38)\end{array}$ & $P$ value \\
\hline Age (years) & $53.5 \pm 8.0$ & $52.4 \pm 7.8$ & 0.279 & $52.9 \pm 6.8$ & $52.7 \pm 7.1$ & 0.938 \\
\hline Uric acid (mg/dl) & $5.88 \pm 1.17$ & $5.75 \pm 1.09$ & 0.370 & $6.29 \pm 1.34$ & $6.22 \pm 1.1$ & 0.824 \\
\hline Systolic blood pressure $(\mathrm{mmHg})$ & $121.7 \pm 15.1$ & $122.1 \pm 13.5$ & 0.859 & $128.3 \pm 16.0$ & $126.6 \pm 10.6$ & 0.585 \\
\hline Diastolic blood pressure $(\mathrm{mmHg})$ & $71.0 \pm 9.7$ & $71.3 \pm 8.5$ & 0.814 & $76.7 \pm 10.9$ & $75.8 \pm 8.4$ & 0.665 \\
\hline Total cholesterol (mg/dl) & $203.1 \pm 36.2$ & $199.5 \pm 33.3$ & 0.436 & $203.3 \pm 30.9$ & $207.3 \pm 29.1$ & 0.558 \\
\hline HDL cholesterol (mg/dl) & $56.3 \pm 14.1$ & $61.0 \pm 17.5$ & 0.023 & $48.1 \pm 10.0$ & $48.4 \pm 11.0$ & 0.924 \\
\hline Triglyceride $(\mathrm{mg} / \mathrm{dl})$ & $124.1 \pm 65.5$ & $112.0 \pm 50.6$ & 0.134 & $144.6 \pm 51.9$ & $166.4 \pm 78.1$ & 0.142 \\
\hline$\gamma$-GTP (IU/1) & $59.4 \pm 72.4$ & $63.6 \pm 62.1$ & 0.647 & $85.5 \pm 91.6$ & $63.0 \pm 35.9$ & 0.160 \\
\hline Creatinine (mg/dl) & $0.81 \pm 0.11$ & $0.79 \pm 0.10$ & 0.176 & $0.81 \pm 0.13$ & $0.80 \pm 0.12$ & 0.678 \\
\hline
\end{tabular}

Age, serum uric acid levels, systolic blood pressure, diastolic blood pressure, serum total cholesterol levels, serum HDL cholesterol levels, serum triglyceride levels, serum $\gamma$-GTP levels, and serum creatinine levels are given as mean \pm SD

All $P$ values depict the significance of differences between ND2-237Leu and ND2-237Met

Table 2 Analysis of covariance for serum uric acid levels

\begin{tabular}{lcc}
\hline & \multicolumn{2}{l}{$F$ value $(P$ value $)$} \\
\cline { 2 - 3 } & BMI $<25$ & BMI $\geq 25$ \\
\hline ND2-237 Leu/Met & $0.45(0.503)$ & $0.01(0.924)$ \\
Habitual drinking & $2.65(0.105)$ & $0.29(0.594)$ \\
Habitual smoking & $0.97(0.327)$ & $0.07(0.798)$ \\
ND2-237 Leu/Met $\times$ habitual drinking & $4.72(0.031)$ & $0.69(0.409)$ \\
ND2-237 Leu/Met $\times$ habitual smoking & $0.04(0.836)$ & $0.25(0.616)$ \\
Age & $0.04(0.851)$ & $2.63(0.109)$ \\
Body mass index & $0.66(0.418)$ & $2.33(0.132)$ \\
Systolic blood pressure & $0.63(0.427)$ & $0.16(0.686)$ \\
Diastolic blood pressure & $1.03(0.310)$ & $0.50(0.481)$ \\
ln (triglycerides) & $9.98(0.002)$ & $0.02(0.888)$ \\
ln $(\gamma$-GTP) & $1.10(0.294)$ & $3.56(0.064)$ \\
Creatinine & $22.3(<0.001)$ & $3.86(0.054)$ \\
\hline
\end{tabular}

In ANCOVA, some independent variables were numerically coded: ND2-237 Leu/Met genotypes (Leu=0, Met=1), habitual drinking (non-daily alcohol drinkers $=0$, daily alcohol drinkers $=1$ ), and habitual smoking (non-smoker $=0$, current smoker=1). ND2-237 Leu/Met×habitual drinking represents interaction between ND2-237 Leu/Met and habitual drinking. ND2-237 Leu/Metxhabitual smoking represents interaction between ND2-237 Leu/Met and habitual smoking. Serum triglyceride levels and serum $\gamma$-GTP levels are logarithm-transformed [ln (triglycerides) and $\ln (\gamma-\mathrm{GTP})]$

of the three other subgroups $(\mathrm{OR}=4.06,95 \% \mathrm{CI}$ 1.27-13.0, $\quad P=0.018 ; \quad \mathrm{OR}=2.59, \quad 95 \%$ CI $1.12-6.00$, $P=0.027$; or $\mathrm{OR}=2.49$, 95\% CI $1.23-5.06, P=0.012$, respectively). After adjustment, a significant OR for SUA levels $\geq 7.0 \mathrm{mg} / \mathrm{dl}$ was observed in daily drinkers with ND2-237Leu when compared to non-daily drinkers with ND2-237Met $(\mathrm{OR}=3.53$, 95\% CI 1.00 12.4, $P=0.049)$. In $B M I \geq 25$ subjects, the $\mathrm{OR}$ for hyperuricemia in daily drinkers with ND2-237Leu was lower when compared with other types, but this difference was not significant (data not shown).
Table 3 Multiple regression analysis for serum uric acid levels in $\mathrm{BMI}<25$ subjects

\begin{tabular}{lcc}
\hline & ND2-237Leu & ND2-237Met \\
\hline Habitual drinking & $0.5815^{*}$ & -0.0861 \\
Habitual smoking & 0.1470 & 0.1392 \\
Age (years) & 0.0020 & -0.0100 \\
Body mass index $\left(\mathrm{kg} / \mathrm{m}^{2}\right)$ & -0.0237 & -0.0454 \\
Systolic blood pressure $(\mathrm{mmHg})$ & -0.0179 & 0.0079 \\
Diastolic blood pressure (mmHg) & 0.0292 & -0.0037 \\
ln (triglycerides (mg/dl)) & $0.5140^{*}$ & 0.3293 \\
$\ln (\gamma$-GTP (IU/l)) & 0.0528 & 0.1878 \\
Creatinine (mg/dl) & $3.3606^{* *}$ & 2.5858 \\
\hline
\end{tabular}

Values indicate partial regression coefficients. In multiple regression analysis, some independent variables were numerically coded: habitual drinking (non-daily drinkers=0, daily drinkers=1), and habitual smoking (non-smokers $=0$, current smokers $=1$ ). Serum triglyceride levels and serum $\gamma$-GTP levels are logarithm-transformed [ln (triglycerides) and $\ln (\gamma$-GTP)]

$* P<0.005, * * P<0.001$

\section{Discussion}

This report suggests that ND2-237 Leu/Met (Mt5178 C/A) polymorphism modulates the effects of daily alcohol consumption on SUA levels. In nonobese $(\mathrm{BMI}<25)$ men, SUA levels were significantly higher in daily drinkers with ND2-237Leu than in non-daily drinkers with ND2-237Leu; no significant differences were observed in SUA levels between daily- and nondaily drinkers with ND2-237Met. Even in nonobese Japanese men with the ND2-237Leu genotype, daily habitual drinking may be a risk factor for hyperuricemia (SUA $\geq 6.5 \mathrm{mg} / \mathrm{dl}$ or $\mathrm{SUA} \geq 7.0 \mathrm{mg} / \mathrm{dl}$ ).

Several epidemiological and clinical studies have reported that the ND2-237Leu genotype may be more susceptible to lifestyle-related adult-onset diseases, such as myocardial infarction (Mukae et al. 2003; 
Takagi et al. 2004), cerebrovascular disorders (Ohkubo et al. 2002) and type 2 diabetes (Wang et al. 2001), when compared to ND2-237Met. ND2-237Met may exert antiatherogenic effects (Kokaze et al. 2001;
Matsunaga et al. 2001). We previously reported that this polymorphism may be associated with blood pressure (Kokaze et al. 2004), serum lipid levels (Kokaze et al. 2001, 2003), and FPG levels and glucose

Table 4 Comparison of serum uric acid levels between non-daily drinkers and daily drinkers by ND2-237 Leu/Met genotype (adjusted)

\begin{tabular}{|c|c|c|c|c|}
\hline & \multicolumn{2}{|l|}{ ND2-237Leu } & \multicolumn{2}{|l|}{ ND2-237Met } \\
\hline & Non-daily drinkers & Daily drinkers & Non-daily drinkers & Daily drinkers \\
\hline \multicolumn{5}{|l|}{$\mathrm{BMI}<25$} \\
\hline$N$ & 88 & 63 & 48 & 42 \\
\hline SUA (mg/dl) & $5.62 \pm 1.09$ & $6.18 \pm 1.08 *$ & $5.84 \pm 1.06$ & $5.77 \pm 1.07$ \\
\hline \multicolumn{5}{|l|}{$\mathrm{BMI} \geq 25$} \\
\hline$N$ & 24 & 18 & 21 & 17 \\
\hline SUA (mg/dl) & $6.42 \pm 1.45$ & $6.01 \pm 1.35$ & $6.22 \pm 1.33$ & $6.28 \pm 1.32$ \\
\hline
\end{tabular}

Serum uric acid (SUA): mean \pm SD. Adjusted for age, BMI, habitual smoking, systolic blood pressure, diastolic blood pressure, logarithm-transformed serum triglyceride levels, logarithm-transformed serum $\gamma$-GTP levels, and serum creatinine levels. Daily drinkers were defined as those who consume alcohol every day. Non-daily drinkers were defined as those who consume alcohol one or more times per week but not every day, those who consume alcohol less once per week, or non-/ex-drinkers. Bonferroni correction for multiple comparisons was applied

$* P<0.05$ versus non-daily drinkers with ND2-237Leu

Table 5 Odds ratios (OR) and 95\% confidence intervals (CI) for hyperuricemia by ND2-237 Leu/Met genotype and habitual drinking in $\mathrm{BMI}<25$ subjects

\begin{tabular}{|c|c|c|c|}
\hline \multicolumn{4}{|l|}{$\mathrm{SUA} \geq 6.5 \mathrm{mg} / \mathrm{dl}$} \\
\hline \multicolumn{3}{|l|}{ Reference group } & \multirow{2}{*}{$\begin{array}{l}\text { Daily drinkers with } \\
\text { ND2-237Leu } 49.2 \%^{\mathrm{a}}(31 / 63) \\
2.61(1.17-5.84)^{*}\end{array}$} \\
\hline Non-daily drinkers with ND2-237Met & $27.1 \%^{\mathrm{a}}(13 / 48)$ & OR $(95 \% \mathrm{CI})$ & \\
\hline & & Adjusted $\mathrm{OR}^{\mathrm{c}}(95 \% \mathrm{CI})$ & $2.24(0.92-5.47)$ \\
\hline \multirow[t]{2}{*}{ Daily drinkers with ND2-237Met } & $19.1 \%^{\mathrm{a}}(8 / 42)$ & OR $(95 \% \mathrm{CI})$ & $4.12(1.65-10.28)^{* * *}$ \\
\hline & & Adjusted $\mathrm{OR}^{\mathrm{c}}(95 \% \mathrm{CI})$ & $3.26(1.14-9.29)^{*}$ \\
\hline \multirow[t]{2}{*}{ Non-daily drinkers with ND2-237Leu } & $23.9 \%^{\mathrm{a}}(21 / 88)$ & OR $(95 \% \mathrm{CI})$ & $3.09(1.54-6.20)^{* * *}$ \\
\hline & & Adjusted $\mathrm{OR}^{\mathrm{c}}(95 \% \mathrm{CI})$ & $3.22(1.39-7.45)^{* *}$ \\
\hline \multirow{2}{*}{$\begin{array}{l}\text { Non-daily drinkers with ND2-237Met, } \\
\text { daily drinkers with ND2-237Met, and } \\
\text { non-daily drinkers with ND2-237Leu }\end{array}$} & $23.6 \%^{\mathrm{a}}(42 / 178)$ & OR $(95 \% \mathrm{CI})$ & $3.14(1.72-5.73) * * * *$ \\
\hline & & Adjusted $\mathrm{OR}^{\mathrm{c}}(95 \% \mathrm{CI})$ & $2.90(1.49-5.65)^{* * *}$ \\
\hline \multicolumn{4}{|l|}{$\mathrm{SUA} \geq 7.0 \mathrm{mg} / \mathrm{dl}$} \\
\hline \multirow[t]{2}{*}{ Reference group } & & & Daily drinkers with \\
\hline & & & ND2-237Leu $27.0 \%$ b $(17 / 63)$ \\
\hline \multirow[t]{2}{*}{ Non-daily drinkers with ND2-237Met } & $8.3 \%^{\mathrm{b}}(4 / 48)$ & OR $(95 \% \mathrm{CI})$ & $4.06(1.27-13.0)^{*}$ \\
\hline & & Adjusted OR ${ }^{c}(95 \%$ CI) & $3.53(1.00-12.4)^{*}$ \\
\hline \multirow[t]{2}{*}{ Daily drinkers with ND2-237Met } & $19.1 \%^{\mathrm{b}}(8 / 42)$ & OR $(95 \% \mathrm{CI})$ & $1.57(0.61-4.06)$ \\
\hline & & Adjusted OR ${ }^{c}(95 \%$ CI $)$ & $1.29(0.43-3.85)$ \\
\hline \multirow[t]{2}{*}{ Non-daily drinkers with ND2-237Leu } & $12.5 \%^{\mathrm{b}}(11 / 88)$ & OR $(95 \% \mathrm{CI})$ & $2.59(1.12-6.00)^{*}$ \\
\hline & & Adjusted $\mathrm{OR}^{\mathrm{c}}(95 \% \mathrm{CI})$ & $2.65(0.96-7.37)$ \\
\hline \multirow{2}{*}{$\begin{array}{l}\text { Non-daily drinkers with ND2-237Met, } \\
\text { daily drinkers with ND2-237Met, and } \\
\text { non-daily drinkers with ND2-237Leu }\end{array}$} & $12.9 \%^{\mathrm{b}}(23 / 178)$ & OR $(95 \% \mathrm{CI})$ & $2.49(1.23-5.06)^{*}$ \\
\hline & & Adjusted OR ${ }^{\mathrm{c}}(95 \% \mathrm{CI})$ & $2.15(0.97-4.77)$ \\
\hline
\end{tabular}

SUA serum uric acid; $O R$ odds ratio; $95 \%$ CI $95 \%$ confidence interval

${ }^{\text {a }}$ Frequency of subjects with SUA levels $\geq 6.5 \mathrm{mg} / \mathrm{dl}$

${ }^{\mathrm{b}}$ Frequency of subjects with SUA levels $\geq 7.0 \mathrm{mg} / \mathrm{dl}$

${ }^{c} \mathrm{OR}$ adjusted for age, body mass index, habitual smoking, systolic blood pressure, diastolic blood pressure, logarithm-transformed serum triglyceride levels, logarithm-transformed serum $\gamma$-GTP levels, and serum creatinine levels

$* P<0.05, * * P<0.01, * * * P<0.005, * * * * P<0.001$ 
tolerance (Kokaze et al. 2005) in healthy Japanese people. This polymorphism is, thus, pathologically, biophysically, and biochemically associated with overall health.

Longevity-associated ND2-237 Leu/Met polymorphism reportedly influences the effects of alcohol consumption on blood pressure (Kokaze et al. 2004), serum TG levels (Kokaze et al. 2003), FPG levels, and response to 75-g-OGTT (Kokaze et al. 2005), and, as shown in this paper, SUA levels. The amino acid change from leucine to methionine at residue 237 of NADH dehydrogenase subunit-2 may bring about a functional change to NADH dehydrogenase. NADH dehydrogenase, namely, complex I of the electron transport chain of mitochondria, is involved in the ethanol-induced production of reactive oxygen species (ROS) (Bailey et al. 1999). Methionine residues, probably including ND2-237Met, act as endogenous antioxidants (Levine et al. 1996). Moreover, purine catabolism, of which the final product is uric acid, provides a homeostatic mechanism to protect mitochondria from ROS (Kristal et al. 1999). One possible mechanism is the biophysical and biochemical differences in the generation of ROS and/or in the sensitivity to ROS between ND2-237Leu and ND2-237Met. The interaction between ND2-237 Leu/Met polymorphism and habitual drinking on FPG levels and glucose tolerance (Kokaze et al. 2005) or SUA levels may vary with BMI. In BMI $<22$ male subjects, FPG levels and plasma glucose levels at $60 \mathrm{~min}$ and $120 \mathrm{~min}$ after glucose load (75-g-OGTT) were significantly lower in the ND2-237Met genotype than in the ND2-237Leu genotype. However, in $\mathrm{BMI} \geq 22$ male subjects, FPG levels were significantly higher in the ND2-237Met genotype than in the ND2-237Leu genotype. BMI status possibly modifies the functional differences between the ND2-237 Leu/Met genotypes. To identify these mechanisms, further biophysical and biochemical investigation is required.

Several genetic polymorphisms are reportedly associated with SUA levels (Hashimoto et al. 2002; Liberopoulos et al. 2005; Masuo et al. 2005; Nishio et al. 2005; Suwazono et al. 2006). Hashimoto et al. (2002) demonstrated that the $\mathrm{ADH} 2$ genotype is involved in SUA levels in relation to alcohol consumption. Nishio et al. (2005) speculated on the interaction between the ecNOS genotype and alcohol drinking on SUA levels. Longevity-associated ND2-237 Leu/Met polymorphism may also modify the effects of alcohol consumption on SUA levels. Consequently, genegene-environmental and gene-gene-gene-environmental interaction on SUA levels should be considered.
In addition to the small sample size, a potential weakness of this paper is the evaluation of habitual drinking based on the frequency of alcohol consumption. It has been reported that the volume of alcohol consumption is associated with the risk of hyperuricemia or gout (Nakanishi et al. 1999; Sugie et al. 2005). Nishimura et al. (1994) demonstrated that even small amounts of alcohol considerably increase SUA levels in daily drinkers, but not in non-daily drinkers. Their observation indicates that daily alcohol intake modifies purine metabolism, resulting in increased SUA levels. Both the volume of alcohol intake and frequency of alcohol consumption appear to be crucial in increasing SUA levels. We also used this evaluation (frequency of alcohol drinking) in previous reports (Kokaze et al. 2003, 2004, 2005), and the interaction, if any, between ND2-237 Leu/Met genotype and volume of alcohol intake on SUA levels warrants further investigation in a larger group of subjects.

In conclusion, this cross-sectional study demonstrates that longevity-associated ND2-237 Leu/Met (Mt5178 C/A) polymorphism may influence the effects of habitual drinking on SUA levels in middle-aged nonobese $(\mathrm{BMI}<25)$ Japanese men. To the best of our knowledge, this is a novel gene-lifestyle interaction on SUA levels. Even among nonobese men, the ND2237Leu genotype should avoid daily alcohol drinking in order to lower the risk of hyperuricemia (SUA $\geq 6.5 \mathrm{mg} / \mathrm{dl}$ or $\mathrm{SUA} \geq 7.0 \mathrm{mg} / \mathrm{dl}$ ). Considering that the ND2-237Leu genotype is overwhelmingly dominant worldwide (Cann et al. 1987), our findings may contribute to the establishment of personalized prevention of hyperuricemia, gout, or cardiovascular disease based on genotyping.

Acknowledgments This study was supported, in part, by grantsin-aid from the Ministry of Education, Culture, Sports, Science and Technology of Japan (no. 14570355 and no. 18590572) and the Chiyoda Mutual Life Foundation, Tokyo, Japan.

\section{References}

Alderman M, Aiyer KJ (2004) Uric acid: role in cardiovascular disease and effects of losartan. Curr Med Res Opin 20(3):369-379

Bailey SM, Pietsch EC, Cunningham CC (1999) Ethanol stimulates the production of reactive oxygen species at mitochondrial complexes I and III. Free Radic Biol Med 27 (7-8):891-900

Campion EW, Glynn RJ, DeLabry LO (1987) Asymptomatic hyperuricemia. Risks and consequences in the Normative Aging Study. Am J Med 82(3):421-426

Cann RL, Stoneking M, Wilson AC (1987) Mitochondrial DNA and human evolution. Nature 325(6099):31-36 
Hashimoto Y, Nakayama T, Futamura A, Omura M, Nakarai H, Nakahara K (2002) Relationship between genetic polymorphisms of alcohol-metabolizing enzymes and changes in risk factors for coronary heart disease associated with alcohol consumption. Clin Chem 48(7):1043-1048

Japanese Society of Gout and Nucleic Acid Metabolism (2002) Guidelines for the management of hyperuricemia and gout (in Japanese)

Johnson RJ, Kang DH, Feig D, Kivilighn S, Kanellis J, Watanabe S, Tuttle KR, Rodrigues-Iturbe B, Herrera-Acosta J, Mazzali M (2003) Is there a pathogenetic role for uric acid in hypertension and cardiovascular and renal disease? Hypertension 41(6):1183-1190

Kokaze A, Ishikawa M, Matsunaga N, Yoshida M, Sekine Y, Teruya K, Takeda N, Sumiya Y, Uchida Y, Takashima Y (2001) Association of the mitochondrial DNA 5178 A/C polymorphism with serum lipid levels in the Japanese population. Hum Genet 109(5):521-525

Kokaze A, Ishikawa M, Matsunaga N, Yoshida M, Sekine Y, Sekiguchi K, Satoh M, Harada M, Teruya K, Takeda N, Uchida Y, Tsunoda T, Takashima Y (2003) Longevityassociated mitochondrial DNA 5178 A/C polymorphism modulates effects of daily drinking and cigarette consumption on serum triglyceride levels in middle-aged Japanese men. Exp Gerontol 38(10):1071-1076

Kokaze A, Ishikawa M, Matsunaga N, Yoshida M, Sekine Y, Sekiguchi K, Harada M, Satoh M, Teruya K, Takeda N, Fukazawa F, Uchida Y, Takashima Y (2004) Longevityassociated mitochondrial DNA $5178 \mathrm{~A} / \mathrm{C}$ polymorphism and blood pressure in the Japanese population. J Hum Hypertens 18(1):41-45

Kokaze A, Ishikawa M, Matsunaga N, Yoshida M, Makita R, Satoh M, Teruya K, Sekiguchi K, Masuda Y, Harada M, Uchida Y, Takashima Y (2005) Longevity-associated mitochondrial DNA $5178 \mathrm{C} / \mathrm{A}$ polymorphism is associated with fasting plasma glucose levels and glucose tolerance in Japanese men. Mitochondrion 5(6):418-425

Kono S, Shinchi K, Imanishi K, Honjo S, Todoroki I (1994) Behavioural and biological correlates of serum uric acid: a study of self-defence officials in Japan. Int $\mathbf{J}$ Epidemiol 23(3):517-522

Kristal BS, Vigneau-Callahan KE, Moskowitz AJ, Matson WR (1999) Purine catabolism: links to mitochondrial respiration and antioxidant defenses? Arch Biochem Biophys 370(1):22-33

Levine RL, Mosoni L, Berlett BS, Stadtman ER (1996) Methionine residues as endogenous antioxidants in proteins. Proc Natl Acad Sci USA 93(26):15036-15040

Liberopoulos EN, Miltiadous GA, Athyros VG, Ganotakis M, Cariolou M, Bairaktari E, Elisaf MS (2005) Effect of apolipoprotein $\mathrm{E}$ polymorphism on serum uric acid levels in healthy subjects. J Investig Med 53(3):116-122

Lin KC, Lin HY, Chou P (2000) Community based epidemiological study on hyperuricemia and gout in Kin-Hu, Kinmen. J Rheumatol 27(4):1045-1050

Loenen HM, Eshuis H, Lowik MR, Schouten EG, Hulshof KF, Odink J, Kok FJ (1990) Serum uric acid correlates in elderly men and women with special reference to body composition and dietary intake (Dutch Nutrition Surveillance System). J Clin Epidemiol 43(12):1297-1303

Masuo K, Katsuya T, Fu Y, Rakugi H, Ogihara T, Tuck ML (2005) Lys418Asn polymorphism of the alpha2-adrenoceptor gene relates to serum uric acid levels but not to insulin sensitivity. Hypertension 46(1):144-450
Matsunaga H, Tanaka Y, Tanaka M, Gong JS, Zhang J, Nomiyama T, Ogawa O, Ogihara T, Yamada Y, Yagi K, Kawamori R (2001) Antiatherogenic mitochondrial genotype in patients with type 2 diabetes. Diabetes Care 24(3):500-503

Matsuzawa Y, Inoue S, Ikeda Y, Sakata T, Saitoh K, Satoh Y, Sirai K, Ohno M, Miyazaki S, Tokunaga K, Fukagawa K, Yamanouchi K, Nakamura T (The committee on the diagnosis and classification criteria of obesity, Japan Society for the study of obesity) (2000) A new criteria of judgment of obesity and diagnosis of pathological obesity (in Japanese). J Jap Soc Study Obes 6:18-28

Mukae S, Aoki S, Itoh S, Sato R, Nishio K, Iwata T, Katagiri T (2003) Mitochondrial 5178A/C genotype is associated with acute myocardial infarction. Circ J 67(1):16-20

Nakanishi N, Tatara K, Nakamura K, Suzuki K (1999) Risk factors for the incidence of hyperuricaemia: a 6-year longitudinal study of middle-aged Japanese men. Int J Epidemiol 28(5):888-893

Nishimura T, Shimizu T, Mineo I, Kawachi M, Ono A, Nakajima H, Kuwajima M, Kono N, Matsuzawa Y (1994) Influence of daily drinking habits on ethanol-induced hyperuricemia. Metabolism 43(6):745-748

Nishio K, Suzuki K, Ito Y, Naito M, Yamamoto K, Tamakoshi A, Hamajima N (2005) Possible interactions of the endothelial constitutive nitric oxide synthase genotype with alcohol drinking and walking time for high serum uric acid levels among Japanese. Metabolism 54(10):1302-1308

Ohkubo R, Nakagawa M, Ikeda K, Kodama T, Arimura K, Akiba S, Saito M, Ookatsu Y, Atsuchi Y, Yamano Y, Osame M (2002) Cerebrovascular disorders and genetic polymorphisms: mitochondrial DNA5178C is predominant in cerebrovascular disorders. J Neurol Sci 198(1-2):31-35

Sugie T, Imatou T, Miyazaki M, Une H (2005) The effect of alcoholic beverage type on hyperuricemia in Japanese male office workers. J Epidemiol 15(2):41-47

Suwazono Y, Kobayashi E, Uetani M, Miura K, Morikawa Y, Ishizaki M, Kido T, Nakagawa H, Nogawa K (2006) The -1438A/G polymorphism in the 5-hydroxytryptamine receptor $2 \mathrm{~A}$ gene is related to hyperuricemia, increased gamma-glutamyl transpeptidase and decreased high-density lipoprotein cholesterol level in the Japanese population: a prospective cohort study over 5 years. Int $\mathrm{J}$ Mol Med 17(1):77-82

Takagi K, Yamada Y, Gong JS, Sone T, Yokota M, Tanaka M (2004) Association of a 5178C $\rightarrow$ A (Leu237Met) polymorphism in the mitochondrial DNA with a low prevalence of myocardial infarction in Japanese individuals. Atherosclerosis 175(2):281-286

Tanaka M, Gong JS, Zhang J, Yoneda M, Yagi K (1998) Mitochondrial genotype associated with longevity. Lancet 351(9097):185-186

Tomita M, Mizuno S, Yamanaka H, Hosoda Y, Sakuma K, Matsuoka Y, Okada M, Yamaguchi M, Yoshida H, Morisawa H, Murayama T (2000) Does hyperuricemia affect mortality? A prospective cohort study of Japanese male workers. J Epidemiol 10(6):403-409

Wang D, Taniyama M, Suzuki Y, Katagiri T, Ban Y (2001) Association of the mitochondrial DNA 5178A/C polymorphism with maternal inheritance and onset of type 2 diabetes in Japanese patients. Exp Clin Endocrinol Diabetes 109(7):361-364

Wortmann RL (2002) Gout and hyperuricemia. Curr Opin Rheumatol 14(3):281-286 